\title{
Teoria da Entidade versus Teoria dos Fundos: uma análise da evidenciação das demonstrações financeiras de uma organização sem fins lucrativos
}

\author{
Entity Theory versus Theory Funds: an analysis of disclosure of financial statements of a \\ nonprofit organization
}

\author{
Gislaine Aparecida Santana \\ Sediyama \\ gislaine.santana@ufv.br
}

UFV

Cleberson Luiz Santos de Paula

clspaula@hotmail.com

UFMG
Romualdo Douglas Colauto

rdcolauto@ufpr.br

UFPR

Gideão José Pinto Oliveira

ggideao@hotmail.com

UNIVERSO

\section{Resumo}

As associações sem finalidade lucrativa não possuem legislação específica para evidenciação de suas Demonstrações Financeiras (DFs) e por isso, são obrigadas a prepará-las conforme as normas para as organizações com finalidades lucrativas. Como a totalidade das rendas arrecada pelas organizações sem fins lucrativos possui destinação específica, a utilização da teoria dos fundos para evidenciação das DFs pode tornar-se a mais adequada para este tipo de entidade. Assim, objetivou-se com este artigo demonstrar a evidenciação do Patrimônio Líquido em uma organização sem fins lucrativos sob a ótica da Teoria dos Fundos. A pesquisa caracterizada como exploratória, buscou converter as DFs de uma organização sem finalidade lucrativa, elaboradas de acordo com a Teoria da Entidade, em DFs elaboradas segundo os princípios da Teoria dos Fundos. O modelo de DFs utilizado no estudo encontra respaldo no Pronunciamento SFAS 117 do American Institute of Certified Public Accountants de 1993, o qual identifica se os recursos arrecadados apresentam restrições temporárias, permanentes ou nenhum tipo de restrição de uso pela organização. Os resultados mostram que a conversão permite ao usuário das informações contábeis identificarem o patrimônio da organização de acordo com a sua finalidade e/ou restrição. Desse modo, a organização em 
estudo apresentou um patrimônio quase em sua totalidade com característica de restrição de uso. Além de revelar um superávit consolidado no Resultado do Exercício pelo modelo da Teoria da Entidade e um déficit quando segregado por fundos.

Palavras-chave: Teoria da Entidade. Teoria dos Fundos. Organizações sem fins lucrativos.

\begin{abstract}
The non-profit organizations don't have specific legislation for disclosure of their financial statements (FDs) and therefore are required to prepare them as the rules for profit organizations. As the full rents earrings by nonprofit organizations have a specific destination, using the theory of the funds for the disclosure of FDs may become more appropriate for this type of entity. Thus, the aim of this article was to demonstrate the disclosure of equity in a non-profit organization from the perspective of the Theory of the Funds. The survey characterized as exploratory, sought to convert the FDs of a non-profit organization, prepared in accordance with the Theory of the Entity in FDs prepared according to the principles of the Theory of the Funds. The model used in the study of FDs is supported by SFAS 117 in the American Institute of Certified Public Accountants, 1993, which identifies whether the funds raised have restrictions temporary, permanent or any restriction of use by the organization. The results show that conversion allows the user of accounting information to identify the assets of the organization according of their purpose and/or restriction. Thus, the organization studied showed a heritage almost entirely with characteristic of use restriction. Besides revealing a earned surplus in the consolidated in the result of the exercise by the model of the Theory of the Entity and a deficit when segregated by fund.
\end{abstract}

Keywords: Theory of the Entity. Theory of the Funds. Non-profit organizations.

Artigo recebido em: 20.01.2013; Aceito em: 01.04.2013

\title{
1 INTRODUÇÃO
}

O excesso de obrigações institucionais do Estado instigou o aparecimento de diversas organizações com atividades tipicamente públicas, apesar de serem pessoas jurídicas de direito privado, com objetivos estritamente sociais e não econômicos. Estas associações que formam o Terceiro Setor são instituições com propósitos específicos de provocar mudanças sociais e cujo patrimônio é constituído, mantido e ampliado, a partir de contribuições, doações e subvenções e que, de modo algum, se reverte para os seus membros ou mantenedores (OLAK, 1996:45) 
Por muitas vezes surgirem de iniciativas de comunidades, cujos gestores detêm pouca ou nenhuma experiência na prática gerencial, muitas destas associações apresentam dificuldades em sua gestão. Por isso, tendem a ter seus recursos limitados ou até mesmo cortados. De acordo com Melo et. al (2003) as instituições sem fins lucrativos não se eximem de serem lucrativas, uma vez que os provedores querem saber se os recursos colocados à disposição dos gestores foram realmente aplicados nos projetos institucionais com eficácia e se os resultados gerados foram reinvestidos nas próprias atividades das entidades ou em novos projetos sociais.

Tais aspectos reforçam a exigência de uma gestão mais eficiente e de uma accountability mais forte que possibilite o conhecimento dos resultados alcançados na gestão por todos os usurários da contabilidade. Especialmente, no que tange a maximização dos benefícios sociais gerados a partir dos recursos arrecadados. Nesse sentido, o lucro pode indicar o uso eficiente dos recursos e a escassez pode estar relacionada a não transparência dos recursos arrecadados e das ações efetivamente realizadas.

Segundo Marcovitch (1997:121), "por desempenharem função de interesse público, espera-se que as organizações do Terceiro Setor cultivem a transparência quanto ao seu portfólio de projetos e, também, quanto aos resultados obtidos e os recursos alocados". Assim, o diagnóstico ex-ante e a avaliação ex-post constituem instrumentos determinantes para o êxito e o apoio a ser obtido em iniciativas futuras.

A Teoria Contábil destaca três fatores relevantes que devem ser considerados para registro dos eventos econômicos: 1) quando reconhecer o evento econômico; 2) como mensurar economicamente os ativos e passivos; e 3) como divulgar aos usuários da contabilidade as informações econômico-financeiras que suportam as tomadas de decisões no curto e longo prazo (BATISTA, 1999). Nessa abordagem as teorias do Patrimônio Líquido se destacam por influenciarem os procedimentos contábeis e interpretar a posição econômica de uma entidade de maneira diferente, interferindo na sua evidenciação.

A Teoria da Entidade defende que a entidade é vista como um ente com existência ou personalidade separada. Os fundadores e proprietários não são necessariamente identificados com a existência da entidade em si (HENDRIKSEN; VAN BREDA, 2007). A Teoria dos Fundos centra-se na gestão e no uso apropriado dos ativos. Um fundo é considerado um grupo homogêneo dentro da organização, que possui obrigações específicas. Essas obrigações, por sua vez, podem ser com terceiros (passivo) ou com capital próprio. Em certas situações, a Teoria dos Fundos implica na existência de contabilidade separada para cada um dos fundos existentes nas entidades (NIYAMA e SILVA, 2010).

$\mathrm{Na}$ legislação brasileira, as organizações sem fins lucrativos obedecem aos mesmos princípios das organizações com finalidade lucrativa, sendo a evidenciação de suas demonstrações financeiras interpretadas conforme a Teoria da Entidade. No entanto, a maioria dos recursos captados pelas organizações sem fins lucrativos tem destinação específica, deste modo a Teoria dos Fundos pode ser considerada apropriada para a evidenciação do patrimônio destas organizações. 
Neste sentido, o presente estudo tem por objetivo demonstrar como ocorre a evidenciação do Patrimônio Líquido em uma organização sem fins lucrativos de acordo com a Teoria dos Fundos. Especificamente, pretende-se: (1) apresentar os aspectos caracterizadores da abordagem da Teoria da Entidade e Teoria dos Fundos para evidenciação do Patrimônio Líquido; e (2) adaptar as Demonstrações Financeiras (DFs) de uma organização sem fins lucrativos, elaboradas de acordo com a Lei 6.404/76 à proposta da Teoria dos Fundos.

$\mathrm{O}$ artigo está estruturado da seguinte forma: inicialmente abordam-se as definições e características do Patrimônio Líquido, os Direitos de Propriedade no qual as Teorias da Entidade e dos Fundos estão inseridas; em seguida, caracterizam-se as organizações sem fins lucrativos e a contabilidade por fundos; após, apresenta-se a metodologia do trabalho, os dados e as evidencias e discutem-se os resultados encontrados; por último, fazem-se as conclusões do estudo.

\section{FUNDAMENTAÇÃO TEÓRICA}

\subsection{DEFINIÇÕES E CARACTERÍSTICAS DO PATRIMÔNIO LÍQUIDO}

Hendriksen e Van Breda (2007) mencionam o Patrimônio não é definido independentemente de ativos e passivos, e talvez não possa ser assim definido. Representa a diferença entre ativos e passivos. Numa formulação mais geral, é a diferença entre recursos e obrigações. No entanto, para D'Auria (1956) o Patrimônio é uma combinação de valores econômicos amealhados, formando um conjunto de riqueza destinada a conseguir resultado. Este resultado é obtido pelo acréscimo de riqueza que se consegue, quando se trabalha com elementos positivos e adequados. Assim, os fins patrimoniais serão alcançados por meio da utilização de recursos econômicos aptos para essa finalidade, como os bens atuais disponíveis e os futuros bens econômicos esperados, os quais representam o ativo. Dessa forma, pode-se entender que o ativo é um conjunto de forças positivas que pode conter também uma parte negativa representada pelo passivo exigível de curto ou longo prazo.

O resultado obtido mediante utilização de ativos será mensurado ao comparar-se o Patrimônio Líquido inicial com aquele apresentado ao final do período. Nessa operação estarão refletidos os critérios adotados na mensuração dos ativos e passivos exigíveis, bem como a metodologia utilizada para reconhecer as receitas e despesas. Deste modo, a mensuração e reconhecimento do Patrimônio Líquido estão condicionados a mensuração e reconhecimento do ativo e do passivo.

Segundo Iudícibus (2010) Patrimônio Líquido (PL) é a diferença, em determinado momento, entre o valor do ativo e do passivo, atribuindo-se a este último à conotação restritiva de dívidas e obrigações. Diferencia-se do passivo pelo fato de normalmente os direitos dos acionistas serem residuais aos dos credores; os valores a serem recebidos pelos beneficiários são determinados com menor grau de certeza; não há obrigação para pagamento de valores (não exigíveis), salvo nos casos de dividendos obrigatórios ou retirada do sócio da sociedade; e por não haver uma data determinável para vencimento das obrigações para com os sócios.

R. Cont. Ufba, Salvador-Ba, v. 7, n. 2, p. 04-21, maio-agosto 2013 
Diversas teorias foram estabelecidas para explicação do fenômeno do PL, sem que houvesse uma teoria que se sobrepusesse às demais ou conseguisse explicá-lo em sua plenitude (ABE, 2007). Na ótica da teoria da contabilidade, o PL pode ser visualizado em quatro pontos teóricos distintos: a teoria do proprietário, a teoria da entidade, a teoria dos fundos e pela teoria do comando.

Conforme Kam (1986) a Teoria do Proprietário vê a corporação como instrumento dos proprietários ao invés de como uma entidade com vida própria separada dos acionistas. Ela supõe que os ativos pertencem ao proprietário e que os passivos são obrigações do proprietário. Nesse sentido, pode-se dizer que a definição do IFRS (2012) para o PL de que este seria o interesse residual nos ativos da entidade depois de deduzir todos os passivos, está diretamente ligada com a Teoria da propriedade. Pois, a ideia de ter os ativos e de dever os passivos com a noção de valores que sobram depois do adimplemento das obrigações contratuais é valores que pertencem ao proprietário está no cerne desta teoria.

$\mathrm{Na}$ Teoria da Entidade a empresa é vista como tendo existência, ou mesmo personalidade, separada. Os fundadores e proprietários não são necessariamente identificados com a existência da empresa (HENDRIKSEN e VAN BREDA, 2007). De acordo com a Teoria do Fundo a empresa seria uma unidade operacional, orientada para atividades, como base da contabilidade. Essa área de interesse denominada fundo inclui um grupo de ativos e obrigações e restrições correspondentes, representando funções ou atividades econômicas específicas. Assim, os ativos representam serviços possíveis ao fundo ou unidade operacional, os passivos representam restrições a ativos específicos ou gerais do fundo e o capital investido representa restrições legais ou financeiras ao uso de ativos (HENDRIKSEN e VAN BREDA, 2007). Ao passo que a Teoria do Comando denota que a atenção principal da contabilidade deveria ser centralizada no controle econômico efetivo dos recursos pelos gerentes ou "comandantes" de uma empresa (IUDICIBUS, 2010).

Nota-se que cada uma destas teorias interpreta a posição econômica da empresa de maneira diferente, e apresenta assim uma ênfase distinta quanto ao método de divulgação dos interesses dos diversos portadores de títulos ou grupos interessados, conduzindo a conceitos diferentes de lucro ou métodos distintos de divulgação de direitos ao lucro da empresa.

Segundo Niyama e Silva (2010) as teorias do PL influenciam os procedimentos contábeis, sendo uma referência para a apresentação das demonstrações financeiras. Isto ocorre devido ao fato de que cada teoria interpreta a posição econômica de uma entidade de maneira diferente, interferindo em sua evidenciação. Deste modo, surge à necessidade de se optar por uma das teorias para garantir uma consistência na apresentação das demonstrações financeiras.

\section{DIREITOS DE PROPRIEDADE}

\subsection{TEORIA DA ENTIDADE}

R. Cont. Ufba, Salvador-Ba, v. 7, n. 2, p. 04-21, maio-agosto 2013 
Segundo Iudícibus (2010), a organização possui uma personalidade própria, ou seja, tem uma vida distinta das atividades e dos interesses pessoais dos proprietários de parcelas de seu capital. Assim, o patrimônio líquido em si, na continuidade, pertence à entidade, não permitindo que o acionista retire-se da sociedade, em qualquer momento, levando sua parcela de patrimônio, pois há prazos e regras para isso acontecer. Em conformidade, Hendriksen e Van Breda (2007) acrescentam que a existência de uma entidade empresarial, separada dos negócios e outros interesses pessoais dos proprietários e outros detentores de títulos, são conhecidos em todos os conceitos de proprietários e direitos. Logo, na teoria da entidade, a empresa é vista como tendo existência, ou mesmo personalidade separada.

Niyama e Silva (2010) destacam que o centro de interesse da contabilidade deve ser a entidade, devendo esta ser representada pela igualdade entre os ativos e as obrigações. $\mathrm{Na}$ visão de Paton e Littleton (1940), apud Kam (1986) a teoria da entidade deve ser vista, inicialmente, como respeitando o fato de que a sociedade tem a existência distinta de seus sócios, com uma entidade própria, indo além da convenção da entidade, no que diz respeito à separação entre os negócios e os assuntos pessoais. No entanto, para Littleton (1961) a teoria da entidade estaria ligada a própria ideia de contabilidade de um agente, pois uma vez que uma sociedade tenha existência distinta dos seus formadores de capital, parece com um agente com a propriedade de outro, sem o verdadeiro direito de propriedade e devendo a estes proprietários o dever de gerenciar e de se reportar, a teoria da entidade está ligada à própria ideia de contabilidade de um agente, moldando-se melhor às condições modernas e à sociedade por quotas de responsabilidade limitada.

Conforme Iudicibus (2010) a Teoria da Entidade considera as exigibilidades como reclamos contra a entidade ou mais especificamente, contra os ativos da entidade. De acordo com essa visão, o passivo é considerado como gênero de recursos globais, e que, a entidade tem um funcionamento distinto dos interesses dos detentores de capital. Para Iudícibus (2010), Paton e Littleton (1940) caracterizam bem a Teoria da Entidade quando afirmam que "a ênfase no ponto de vista da entidade requer o tratamento dos ganhos e lucros de negócio como lucro da entidade em si até que a transferência para os participantes individuais tenha sido feita por uma declaração de dividendos”. Li (1960) formulou as seguintes hipóteses à luz da definição da separação entre as entidades, para explicar a Teoria da entidade: (a) objetivo primário de uma sociedade quando ela é incorporada é a e prestar serviços e criar utilidades; (b) a sociedade para atingir seus objetivos irá buscar recursos; (c) uma vez que a sociedade é um centro de imputação de direitos e obrigações, possui capacidade (no sentido jurídico) de contratar com os fornecedores de recursos; (d) após a sua incorporação, o principal objetivo da sociedade passa a ser o da sobrevivência; (e) com este novo objetivo, a sociedade busca atingir e manter competência econômica e financeira.

Outro fator decorrente da mudança de paradigma é o abandono da ideia de patrimônio líquido, pois a equação básica deve ser vista como "Ativos - Equidades" na medida em que os ativos pertençam à sociedade e que os passivos, tanto para terceiros, quanto para os acionistas, são obrigações da firma, e não dos proprietários (KAM, 1986: 37). Conforme expõe Kam (1986: 307) Paton e Littleton (1940) enxergam, tal colocação, como a expressão mais lógica das

R. Cont. Ufba, Salvador-Ba, v. 7, n. 2, p. 04-21, maio-agosto 2013 
condições financeiras da sociedade, isto, por conseguinte, poderia levar a perda da necessidade de se mensurar o patrimônio líquido de forma isolada.

Nesta visão, os ativos são custos adiados na medida em que representam serviços adquiridos pela firma e ainda não entregues aos seus clientes, e que possam futuramente ser convertidos em novos ativos. São oriundos de recursos diversos entregues à sociedade sob alguma forma contratual, que permite a exigência de uma contrapartida futura pelos credores. Desta forma, os credores possuem uma reclamação específica, enquanto os investidores, por força de um diferente tipo de contrato não assinado com a sociedade, possuem uma reclamação residual sobre os ativos em caso de dissolução da sociedade (ABE, 2007). Nesse sentido, o passivo representa a origem dos ativos utilizados nas atividades da sociedade, isto é, a quem e quanto à sociedade tem obrigação de adimplir, por ter recebido recursos para exercer as suas atividades.

Conforme expõe Paton e Littleton (1940), citado por Kam (1986:309), somente o consumo de ativos representa os custos e despesas da sociedade. Por outro lado, as remunerações dos credores que não sejam transformadas diretamente em ativos, são vistos como distribuição dos resultados. Para o autor, a renda gerada pela atividade da sociedade será da sociedade e não de seus proprietários. Por consequência desta teoria, a sociedade é quem irá determinar quando e quanto da renda irá para os proprietários. Na medida em que os proprietários possuem um direito residual sobre os ativos, a renda gerada será contabilizada junto com o capital realizado, demonstrando que após a satisfação dos demais credores, os ativos, na liquidação, serão destinados aos proprietários.

Na percepção de Husband (1938) a sociedade é a sua própria proprietária, os ativos são de propriedade da sociedade, toda riqueza gerada é renda da entidade sociedade até que seja declarada como dividendos, a reserva é PL da entidade e não pode ser adicionado ao capital social para computar o valor de livros da participação dos proprietários, devendo estes ser considerados espécie de passivo. Do ponto de vista da teoria da contabilidade, o patrimônio líquido é conceitualmente equiparado aos passivos da sociedade, não podendo mais ser visto como um resíduo de valores, mas sim como outra fonte de recursos para a sociedade, que serão utilizados para a aquisição de ativos necessários à atividade social.

\subsection{TEORIA DOS FUNDOS}

A Teoria dos Fundos trata a empresa como uma unidade operacional orientada para as atividades. Inclui o grupo de ativos, obrigações e restrições correspondentes, representando funções ou atividades econômicas específicas, onde os ativos representam serviços possíveis ao fundo ou unidade operacional, os passivos as restrições a ativos específicos ou gerais do fundo e o capital investido as restrições legais ou financeiras ao uso de ativos (HENDRIKSEN e VAN BREDA, 2007).

Para Vatter (1963: 367) a teoria do fundo seria uma extensão da teoria da entidade, mas com a diferença que a base da contabilidade não seria o proprietário ou a sociedade, e sim, um grupo

R. Cont. Ufba, Salvador-Ba, v. 7, n. 2, p. 04-21, maio-agosto 2013 
de ativos e um conjunto de atividades ou funções para as quais esses ativos são utilizados. Tal grupo de ativos é chamado de fundo.

Sua teoria oferece uma alternativa para explicar a composição do patrimônio líquido, pois todo o lado direito do balanço seria indicativo das restrições que existem sobre os ativos do lado esquerdo, que surgem tanto de situações legais, de equidade, econômico-financeiras ou por decisões gerenciais. Desse modo, a noção de patrimônio líquido representaria a ideia da restrição que a gerência da sociedade possui em relação aos ativos, após o balanço dos passivos, do que a efetiva representação de um passivo. Assim, pela despersonalização do fundo, não haveria mais um destinatário personificado da informação final sobre o patrimônio líquido (BATISTA, 1999)

A igualdade do balanço teria, então, o formato de "ativos - restrições sobre os ativos", representando a ideia do "fundo", pois os ativos compõem o fundo a ser usado pela administração para realizar as atividades necessárias do fundo. Além disso, todo o resultado do uso dos ativos, isto é, a diferença entre receitas e despesas deve ser distribuída, como retribuição do financiamento das transações ou retido, nas contas do patrimônio líquido (VATTER, 1963).

$\mathrm{Na}$ Teoria do Fundo, as receitas seriam, assim, representativas do aumento do ativo, sem a contrapartida de qualquer obrigação, exceto a restrição final imposta pelo patrimônio líquido "residual equity". Por outro lado, as despesas serviram para representar o uso de serviços específicos para os objetivos do fundo, incluindo, dessa forma, o custo de obtenção de receitas (KAM, 1986).

As duas formas de visão sobre a sociedade, estática quando referente ao retrato efetuado pelo balanço e dinâmico quando representando o resultado do exercício, devem representar a mesma mudança no PL, pois resumem as mesmas informações e cobrem as mesmas situações. A renda fica despersonalizada, pois ao contrário da teoria da propriedade, que requer perda ou ganho de proprietários, e da teoria da entidade, que troca renda do proprietário pela renda da entidade e utiliza à noção de capital e reservas, a Teoria dos Fundos não busca medir para quem a renda é destinada. Desse modo, o demonstrativo de resultado passa a ter uma noção apenas estatística para a produção de relatórios conforme necessidades variadas (ABE, 2007).

Com base no exposto, pode-se dizer que a teoria do fundo serviria para atender diferentes demandas de explicações do uso dos ativos destinados às atividades, sem se preocupar com um destinatário específico personalizado, podendo se moldar a qualquer característica e necessidade dos destinatários da demonstração.

\section{CARACTERIZAÇÃO DAS ORGANIZAÇÕES SEM FINS LUCRATIVOS}

Olak e Nascimento (2010) retratam que não é tarefa fácil buscar uma definição clara e objetiva para as organizações sem fins lucrativos, mas que após a análise de algumas características básicas que diferenciam essas organizações das com fins lucrativos torna-se mais fácil esta definição. 
Segundo Freeman e Shoulders (1993) as principais características das organizações sem fins lucrativos seriam quanto: ao lucro; a propriedade; as fontes de recursos; e as decisões políticas e operacionais. No que tange ao lucro esse não seria a razão de ser dessas entidades. Em relação à propriedade essa pertenceria à comunidade, não sendo, normalmente, caracterizadas pela divisibilidade do capital em partes proporcionais, que podem ser vendidas ou permutadas. Quanto às fontes de recursos, as contribuições com recursos financeiros não dariam direito ao doador de participação proporcional nos bens ou serviços da organização. No que tange às principais decisões políticas e operacionais, as maiores decisões políticas e algumas decisões operacionais são tomadas por consenso de voto, via assembleia geral, por membros de diversos segmentos da sociedade direta ou indiretamente eleitos.

A visão de obtenção de lucro não é o objetivo principal destas organizações, mas ele é necessário para garantir a continuidade de seus objetivos. Quanto a sua propriedade, diferentemente das organizações com fins lucrativos, todo o seu patrimônio não tem um dono específico e não há a divisibilidade dos resultados econômicos alcançados, tudo que se têm e se obtêm com a gestão destas empresas pertence à comunidade como um todo ou um segmento específico dela. Por meio das características citadas acima, Petri (1981, p. 12) definir as organizações sem fins lucrativos, como:

as organizações sem fins lucrativos não são aquelas que não têm rentabilidade. Elas
podem gerar recursos através de: atividades de compra e venda; de industrialização e
venda dos produtos elaborados; e de prestação de serviços, obtendo preço ou
retribuição superior aos recursos sacrificados para sua obtenção, sem por isso
perderem a característica de sem fins lucrativos. O que lhes dá essa característica é o
fato de não remunerarem seus proprietários (acionistas, sócios ou associados) pelos
recursos por eles investidos em caráter permanente (capital social, fundo social ou
patrimônio), com base nos recursos próprios por elas gerados (ganhos ou lucros), e a
eles não reverterem o patrimônio (incluindo os resultados) dessa mesma maneira, no
caso de descontinuidade.

Segundo Andrade (1991, p. 310), as “organizações sem fins lucrativos são aquelas instituições formadas com propósitos sociais, educacionais, religiosos, de saúde ou filantrópicos e aquelas em que, normalmente, não existe interesse na transferência de propriedade e seus membros ou contribuintes não recebem qualquer ganho econômico ou financeiro direto". De modo geral, nota-se que as organizações sem fins lucrativos existem para provocar mudanças nos indivíduos e, consequentemente, na sociedade. Entretanto, cada organização deve definir formal ou informalmente, sua própria filosofia em termos de missão, finalidades ou propósitos básicos.

Segundo Olak e Nascimento (2010, p. 9), as organizações sem fins lucrativos podem ser classificadas sob várias abordagens. Dentre elas, destacam-se: (1) quanto às atividades que desempenham. São compostas pelas entidades de caráter beneficente, filantrópico e caritativo; entidades de assistência à saúde; entidades religiosas; entidades de caráter educacional, cultural, instrutivo, científico, artístico e literário; entidades de caráter recreativo e esportivo; associações de classe; entidades sindicais; sociedades cooperativas; (2) quanto à origem dos

R. Cont. Ufba, Salvador-Ba, v. 7, n. 2, p. 04-21, maio-agosto 2013 
recursos financeiros e materiais. São as entidades que dependem fundamentalmente das subvenções governamentais; e as que não dependem de subvenções governamentais; (3) quanto à extensão dos benefícios sociais. Constituídas pelas entidades que prestam serviços a toda a comunidade irrestrita e incondicionalmente; e se que restringem seus benefícios apenas ao seu quadro social.

\section{CONTABILIDADE POR FUNDOS}

A Contabilidade por Fundos funciona de maneira similar à contabilidade de uma empresa com fins lucrativos com várias filiais ou controladas. Isto é, todo o processo de contabilização das transações ocorridas são efetuadas de maneira individualizada. No caso das organizações sem fins lucrativos, os recursos captados podem ser denominados de fundos. Olak e Nascimento (2010) conceitua este termo como sendo um conjunto de recursos de várias procedências para a consecução de um determinado fim.

Para Summers (1991) um fundo, a unidade básica da contabilidade por fundos, é um conjunto de recursos comprometidos para propósitos específicos. Para fins contábeis, um Fundo é uma entidade muito semelhante a uma empresa por ter contas registrando caixa e outros recursos financeiros, bem como dívidas e Patrimônio líquido".

O American Institute of Certified Public Accountants (AICPA) (2010) conceitua a Contabilidade por Fundos como uma metodologia pela qual os recursos para vários propósitos são classificados, para fins de contabilização e de divulgação, de acordo com atividades ou objetivos, conforme especificados pelos doadores, de acordo com as regras, restrições ou limitações impostas aos recursos externos à instituição ou de conformidade com as deliberações dos órgãos diretivos da entidade. Pode ser considerado, resumidamente, um sistema idêntico ao das organizações com fins lucrativos, com um elenco próprio de contas, possuindo ativos, passivos, patrimônio líquido, receitas/ganhos e despesas/perdas, mas com uma segregação para cada tipo de fundo.

O AICPA (2010) enfatiza que contabilidade por fundos compreende "um conjunto de procedimentos contábeis sob um balancete próprio de contas para cada fundo instituído por ação legal, contratual ou voluntária de uma organização. Os elementos de cada fundo podem incluir ativos, passivos, patrimônio líquido, receitas e despesas. A Contabilidade por Fundos envolve procedimentos segregados de contabilização, embora não necessariamente segregação física de recursos".

Quando uma organização sem fins lucrativos recebe suas contribuições, subvenções ou doações, muitas das vezes estes são recebidos e acompanhados de cláusulas de destinação específica ou não, ou seja, há recursos que podem ser livremente utilizados pelos gestores dos recursos e outros só poderão ser utilizados em atividades específicas de acordo com as regras estabelecidas no documento de doação ou nos propósitos os quais os recursos foram arrecadados (OLAK e NASCIMENTO, 2010).

No Pronunciamento SFAS 117 (1993), o Fasb buscou tratar especificamente dos procedimentos contábeis para organizações sem fins lucrativos. De acordo com este

R. Cont. Ufba, Salvador-Ba, v. 7, n. 2, p. 04-21, maio-agosto 2013 
pronunciamento, os recursos básicos arrecadados por estas instituições originam-se de três categorias diferentes: (1) recebidos sem nenhuma restrição (uso irrestrito): permite a direção/gestores utilizarem os recursos doados/recebidos da forma como lhe convier, desde que cumprido os objetivos da organização; (2) recebidos com restrições temporárias: quando do recebimento dos recursos, os doadores impõe uma restrição do uso destes, obrigando à instituição utilizá-los como especificado, e que é cumprida pelo tempo decorrido ou por ações da instituição; (3) recebidos com restrições permanentes: quando do recebimento dos recursos, os doadores impõe restrições limitando a utilização destes somente em consonância com as determinações do doador.

Desta forma, este tipo de contabilização vem dar mais transparência a evidenciação das informações contábeis nas demonstrações financeiras deste tipo de instituições, visto que os usuários destes demonstrativos necessitam identificar como foi ou até mesmo como está sendo realizadas a aplicações destes recursos e qual o resultado final alcançado pela organização de forma segregada por origem de fundos.

\section{PROCEDIMENTOS METODOLÓGICOS}

A pesquisa caracteriza-se como exploratória, pois têm como objetivo proporcionar maior familiaridade com o problema, com vistas a torná-lo explicito ou formular as hipóteses de uma pesquisa (GIL, 2010). Por isso, a abordagem do problema é qualitativa.

Para operacionalização dos dados e evidências, realizou-se inicialmente uma pesquisa bibliográfica com base em material já elaborado, constituído principalmente de livros e artigos científicos com o objetivo de esclarecer e aprofundar o assunto. Em seguida, foi realizada, em junho de 2008, uma visita à Casa de Apoio a Criança Carente de Contagem onde foram coletados os dados, que consistiram basicamente em Balanço Patrimonial, Balancetes Analíticos, Razão Contábil e o Demonstrativo do Superávit (déficit do exercício), relativos ao exercício de 2007, que serviriam como base para construção dos demonstrativos financeiros com base na contabilidade por fundos.

Estas demonstrações foram convertidas para o software Excel 2007 e por meio de uma análise detalhada do razão contábil, foi possível identificar os lançamentos e separá-los de acordo com o SFAS 117 (1993), que identifica a forma como os recursos arrecadados podem ser utilizados pelas organizações (sem nenhuma restrição, restrição temporária ou restrição permanente). As informações foram extraídas a partir dos balancetes dos centros de custos e de informações financeiras obtidas junto à gestão financeira da Instituição.

Em função da identificação dos conceitos aplicáveis à contabilidade por fundo efetuou-se a classificação dos recursos conforme o pronunciamento SFAS 117, que permitiu chegar ao Balanço Patrimonial e a Demonstração de Atividades do Exercício por Fundos.

\section{DESCRIÇÃO DOS DADOS}

R. Cont. Ufba, Salvador-Ba, v. 7, n. 2, p. 04-21, maio-agosto 2013 
Fundada em 20 de julho de 1994, a Casa de Apoio à Criança Carente de Contagem é uma sociedade civil sem fins lucrativos, de caráter filantrópico, que atua nas áreas de educação, saúde, desenvolvimento social e protagonismo juvenil. Atualmente, a instituição possui três unidades: Casa Abrigo, Centro Educacional e Profissionalizante de Nova Contagem e Centro Educacional Ipê Amarelo, todas no município de Contagem. Os terrenos das três unidades foram doados pela prefeitura do município e as construções realizadas em parcerias com missionários, um grupo de norte-americanos, sociedade civis e empresários.

Os demonstrativos utilizados pela organização em questão estão demonstrados abaixo. No Quadro 1 apresenta-se o Balanço Patrimonial e no Quadro 2 o Demonstrativo de Superávit do Exercício, conforme Legislação Societária vigente.

Quadro 1: Balanço Patrimonial de acordo com a legislação societária.

\begin{tabular}{|l|r|l|r|}
\hline \multicolumn{3}{|c|}{ CASA DE APOIO À CRIANÇA CARENTE DE CONTAGEM } \\
EM 31/12/2007 & TOTAL \\
\hline ATIVO & \multicolumn{1}{|c|}{ TOTAL } & PASSIVO & $\mathbf{4 4 . 8 8 4 , 9 5}$ \\
\hline Circulante & $\mathbf{4 0 1 . 0 9 2 , 0 1}$ & Circulante & 621,56 \\
\hline Caixa e Fundo Fixo & 65,20 & Empréstimos a Pagar & $5.403,14$ \\
\hline Bancos & $314.447,57$ & Salários a Pagar & $17.936,45$ \\
\hline Aplicações Financeiras & $77.234,32$ & Encargos Sociais a Recolher & $20.923,80$ \\
\hline Adiantamento a funcionários & $9.344,92$ & Outras Obrigações & \\
\hline Não Circulante & $\mathbf{1 . 3 1 9 . 8 0 1 , 1 1}$ & & $\mathbf{1 . 3 1 9 . 1 3 1 , 2 2}$ \\
\hline Imobilizado & $183.268,39$ & & $\mathbf{1 . 6 7 6 . 0 0 8 , 1 7}$ \\
\hline Imóveis & $159.962,83$ & Patrimônio Líquido Social & $507.540,86$ \\
\hline Máquinas e Equipamentos & $87.332,38$ & Patrimônio Social & $839.554,93$ \\
\hline Móveis e Utensílios & $26.599,00$ & Superávit Acumulado & $48.085,98$ \\
\hline Veículos & $861.968,62$ & Ajustes de Exercícios Anteriores & $\mathbf{2 8 0 . 8 2 6 , 4 0}$ \\
\hline Construções e Instalações & $\mathbf{6 6 9 , 8 9}$ & Resultado do Exercício & \\
\hline Diferido & 669,89 & & $\mathbf{1 . 7 2 0 . 8 9 3 , 1 2}$ \\
\hline Benfeitorias alugadas & $\mathbf{1 . 7 2 0 . 8 9 3 , 1 2}$ & Total & \\
\hline Total & & \\
\hline Fonte: Dados da pesquisa & \\
\hline
\end{tabular}

Fonte: Dados da pesquisa

\begin{tabular}{|c|c|}
\hline \multicolumn{2}{|c|}{$\begin{array}{c}\text { DEMONSTRATIVO DE ATIVIDADES DO EXERCÍCIO } \\
\text { CASA DE APOIO À CRIANÇA CARENTE DE CONTAGEM } \\
\text { Em 31/12/2007 }\end{array}$} \\
\hline Receitas & TOTAL \\
\hline Receita de Convênios Internacionais & $1.613 .412,38$ \\
\hline Doações & $105.890,56$ \\
\hline Atividades Geradora de Renda & $14.774,53$ \\
\hline Outras Receitas & $14.752,14$ \\
\hline
\end{tabular}




\begin{tabular}{|l|r|} 
Subtotal & $\mathbf{1 . 7 4 8 . 8 2 9 , 6 1}$ \\
\hline Despesas / Receitas Operacionais & $(\mathbf{1 8 . 6 2 7 , 6 9 )}$ \\
\hline Apadrinhamento Brasileiro & $\mathbf{( 3 8 6 . 9 9 5 , 3 6 )}$ \\
\hline Remuneração a Funcionários & $\mathbf{( 8 1 . 9 2 1 , 0 6 )}$ \\
\hline Encargos sociais e Benefícios & $\mathbf{( 4 1 7 . 0 1 1 , 8 5 )}$ \\
\hline Material de Uso e consumo & $\mathbf{( 8 8 . 0 5 3 , 2 8 )}$ \\
\hline Utilidades e Serviços & $\mathbf{( 3 0 0 . 8 4 8 , 8 3 )}$ \\
\hline Serviços de Terceiro & $\mathbf{( 1 8 4 . 2 2 4 , 0 7 )}$ \\
\hline Outras Despesas & $\mathbf{9 . 6 7 8 , 9 3}$ \\
\hline Receita Financeira & $\mathbf{( 1 . 4 6 8 . 0 0 3 , 2 1 )}$ \\
\hline Subtotal & $\mathbf{2 8 0 . 8 2 6 , 4 0}$ \\
\hline Superávit / (Déficit) Operacional &
\end{tabular}

Fonte: Dados da pesquisa

No Quadro 3 apresenta-se o Balanço Patrimonial conforme a Contabilidade por Fundos.

Quadro 3: Balanço Patrimonial conforme a contabilidade por Fundos.

\begin{tabular}{|c|c|c|c|c|c|c|}
\hline \multicolumn{7}{|c|}{$\begin{array}{c}\text { BALANÇO PATRIONIAL (POR FUNDO) } \\
\text { CASA DE APOIO À CRIANÇA CARENTE DE CONTAGEM } \\
\text { Em 31/12/2007 }\end{array}$} \\
\hline Descrição & $\begin{array}{c}\text { Uso } \\
\text { Irrestrito }\end{array}$ & \multicolumn{3}{|c|}{ Uso Internamente Restrito } & $\begin{array}{l}\text { Uso } \\
\text { Externamente } \\
\text { Restrito }\end{array}$ & Consolidado \\
\hline ATIVO & Geral & Imobilizado & Social & Soma & Empréstimos & TOTAL \\
\hline Circulante & $1.297,69$ & & $399.172,76$ & $399.172,76$ & 621,56 & 401.092,01 \\
\hline Caixa e Fundo Fixo & 65,20 & & & & - & 65,20 \\
\hline Bancos & $1.232,49$ & & $313.215,08$ & $313.215,08$ & - & $314.447,57$ \\
\hline Aplicações Financeiras & & & $77.234,32$ & $77.234,32$ & - & $77.234,32$ \\
\hline Adiantamento a funcionários & & & $8.723,36$ & $8.723,36$ & 621,56 & $9.344,92$ \\
\hline Não Circulante & $328.301,09$ & $861.968,62$ & $\mathbf{1 2 9 . 5 3 1 , 4 0}$ & $991.500,02$ & - & $1.319 .801,11$ \\
\hline Imobilizado & $327.631,20$ & $861.968,62$ & $\mathbf{1 2 9 . 5 3 1 , 4 0}$ & $991.500,02$ & - & 1.319.131,22 \\
\hline Imóveis & $183.268,39$ & & & - & & $183.268,39$ \\
\hline Máquinas e Equipamentos & $30.431,43$ & & $129.531,40$ & $129.531,40$ & - & $159.962,83$ \\
\hline Móveis e Utensílios & $87.332,38$ & & - & - & - & $87.332,38$ \\
\hline Veículos & $26.599,00$ & & - & - & - & $26.599,00$ \\
\hline Construções e Instalações & - & $861.968,62$ & - & $861.968,62$ & - & $861.968,62$ \\
\hline Benfeitorias/Imov. Alugados & 669,89 & - & - & - & - & 669,89 \\
\hline Total & 329.598,78 & $861.968,62$ & $528.704,16$ & $1.390 .672,78$ & 621,56 & $1.720 .893,12$ \\
\hline \multicolumn{7}{|l|}{ PASSIVO } \\
\hline Circulante & $20.923,80$ & - & 23.339,59 & $23.339,59$ & 621,56 & 44.884,95 \\
\hline Empréstimos a Pagar & - & - & - & - & 621,56 & 621,56 \\
\hline Salários a Pagar & - & - & $5.403,14$ & $5.403,14$ & - & $5.403,14$ \\
\hline
\end{tabular}




\begin{tabular}{|l|r|r|r|r|r|r|}
\hline Encargos Sociais a Recolher & - & - & $17.936,45$ & $17.936,45$ & - & $17.936,45$ \\
\hline Outras Obrigações & $20.923,80$ & - & - & - & - & $20.923,80$ \\
\hline Patrimônio Líquido Social & $\mathbf{3 0 8 . 6 7 4 , 9 8}$ & $\mathbf{8 6 1 . 9 6 8 , 6 2}$ & $\mathbf{5 0 5 . 3 6 4 , 5 7}$ & $\mathbf{1 . 3 6 7 . 3 3 3 , 1 9}$ & - & $\mathbf{1 . 6 7 6 . 0 0 8 , 1 7}$ \\
\hline PL Irrestrito & $167.433,20$ & - & - & - & - & $167.433,20$ \\
\hline $\begin{array}{l}\text { PL Restrito } \\
\text { Permanentemente }\end{array}$ & & & & & \\
\hline $\begin{array}{l}\text { PL Restrito } \\
\text { Temporariamente }\end{array}$ & - & - & $340.107,66$ & $340.107,66$ & & - \\
\hline Superávit Acumulado & $25.133,00$ & $814.421,93$ & - & $814.421,93$ & $340.107,66$ \\
\hline Ajustes de Exerc. Anteriores & $48.085,98$ & & - & - & - & $839.554,93$ \\
\hline Resultado do Exercício & $68.022,80$ & $47.546,69$ & $165.256,91$ & $212.803,60$ & - & $48.085,98$ \\
\hline Total & $\mathbf{3 2 9 . 5 9 8 , 7 8}$ & $\mathbf{8 6 1 . 9 6 8 , 6 2}$ & $\mathbf{5 2 8 . 7 0 4 , 1 6}$ & $\mathbf{1 . 3 9 0 . 6 7 2 , 7 8}$ & $\mathbf{6 2 1 , 5 6}$ & $\mathbf{1 . 7 2 0 . 8 9 3 , 1 2}$ \\
\hline
\end{tabular}

Fonte: Dados da pesquisa.

O Balanço Patrimonial por fundos demonstra um maior grau de transparência, ao evidenciar as origens e aplicações de recursos relativos à disponibilidade de utilização. Apesar de apresentar um valor elevado no disponível, percebe-se que a utilização deste recurso já apresenta um fim específico: aplicação na consecução da própria atividade, atividade de cunho social.

Do total do ativo consolidado, nota-se que $80 \%$ deles são para uso restrito. Ao passo que do total de recursos do ativo que poderão ser utilizados de forma irrestrita, $99,40 \%$ estão alocados no ativo permanente e que somente $0,60 \%$ são de recursos disponíveis. Desta forma, a reclassificação ou segregação, é de grande utilidade na análise e interpretação dos valores patrimoniais de uma organização sem fins lucrativos, ao demonstrar maior transparência.

Uma dificuldade na operacionalização dos dados foi identificar e classificar o PL quanto ao grau de irrestrito e restrito temporária ou permanentemente. Isto porque o Capital Social é fruto das atividades de mais de 15 anos e como não havia o conceito de contabilidade por fundos, não houve a preocupação em segregar como a orientação da contabilidade por fundos (SFAS 117, 1993; OLAK e NASCIMENTO, 2010). A classificação então foi feita para fins de enquadramento na estrutura do SFAS 117 através de entrevista com o gestor financeiro e com o vice-presidente da organização, hoje, atual relator do conselho fiscal.

No Quadro 4 apresenta o Demonstrativo de Superávit (déficit) do exercício conforme a contabilidade por fundos.

Quadro 4: Demonstrativo de Atividade do Exercício - contabilidade por fundos.

\begin{tabular}{|c|c|c|c|c|c|c|}
\hline \multicolumn{7}{|c|}{$\begin{array}{l}\text { DEMONSTRATIVO DE ATIVIDADES DO EXERCÍCIO (POR FUNDO) } \\
\text { CASA DE APOIO À CRIANÇA CARENTE DE CONTAGEM } \\
\text { Em 31/12/2007 }\end{array}$} \\
\hline Descrição & Uso & \multicolumn{3}{|c|}{ Uso Internamente Restrito } & \multirow{2}{*}{\begin{tabular}{|c|} 
Uso \\
$\begin{array}{c}\text { Externamente } \\
\text { Restrito }\end{array}$ \\
Imobilização \\
\end{tabular}} & \multirow{2}{*}{$\begin{array}{l}\text { Consolidado } \\
\text { TOTAL }\end{array}$} \\
\hline Receitas & Geral & $\begin{array}{l}\text { Convênios } \\
\text { Internacionais }\end{array}$ & $\begin{array}{l}\text { Convênios } \\
\text { Governamentais }\end{array}$ & Outros & & \\
\hline Receita de Convênios & & $519.001,12$ & $1.020 .462,26$ & $73.949,00$ & & 1.613.412,38 \\
\hline
\end{tabular}




\begin{tabular}{|c|c|c|c|c|c|c|}
\hline Doações & $58.343,87$ & & - & - & $47.546,69$ & $105.890,56$ \\
\hline Ativ. Geradora de Renda & & & - & $14.774,53$ & & $14.774,53$ \\
\hline Outras Receitas & & & - & $14.752,14$ & & $14.752,14$ \\
\hline Subtotal & 58.343,87 & $519.001,12$ & $1.020 .462,26$ & $103.475,67$ & $47.546,69$ & $1.748 .829,61$ \\
\hline \multicolumn{7}{|l|}{ Desp. / Rec. } \\
\hline Apadrinhamento & & & & $(18.627,69)$ & & $(18.627,69)$ \\
\hline Rem. a Funcionários & & $(308.172,31)$ & $(78.703,05)$ & $(120,00)$ & & $(386.995,36)$ \\
\hline Encargos Soc. e & & $(64.880,31)$ & $(17.040,75)$ & - & & $(81.921,06)$ \\
\hline Material de Uso e & & $(76.716,98)$ & $(327.315,64)$ & $(12.979,23)$ & & $(417.011,85)$ \\
\hline Utilidades e Serviços & & $(30.704,90)$ & $(47.320,66)$ & $(10.027,72)$ & & $(88.053,28)$ \\
\hline Serviços de Terceiro & & $(112.558,81)$ & $(181.021,32)$ & $(7.268,70)$ & & $(300.848,83)$ \\
\hline Outras Despesas & & $(44.344,61)$ & $(128.110,40)$ & $(11.769,06)$ & & $(184.224,07)$ \\
\hline Receita Financeira & $9.678,93$ & - & - & - & & $9.678,93$ \\
\hline Subtotal & $9.678,93$ & $(637.377,92)$ & $(\mathbf{7 7 9 . 5 1 1 , 8 2 )}$ & $(60.792,40)$ & & $(1.468 .003,21)$ \\
\hline Superávit Operacional & $68.022,80$ & $(118.376,80)$ & $240.950,44$ & $42.683,27$ & $\mathbf{4 7 . 5 4 6 , 6 9}$ & $280.826,40$ \\
\hline
\end{tabular}

Fonte: Dados da pesquisa

Os dados acima revelam que apesar de a entidade em estudo ter apresentado em seu resultado consolidado um superávit Operacional de $\mathrm{R} \$ 280.826,40$, a segregação por fundos possibilitou verificar que os recursos de Uso Internamente Restrito referente aos convênios Internacionais teve saldo negativo, ou seja, apresentou um Déficit. Isso demonstra que os recursos arrecadados por meio de convênios internacionais, a segunda maior fonte de recursos da entidade, não foram suficientes para suportar os gastos (despesas) no período. Indicando a necessidade de um gerenciamento mais eficiente na busca dos melhores resultados.

A visualização dos resultados por tipos de fundos destacam os fundos livres obtidos através de doações genéricas e fundos com fins/projetos específicos, que no exemplo em questão, seriam as verbas internacionais e as verbas governamentais. Além de demonstrar o uso específico deste recurso em termos de despesas.

\section{CONSIDERAÇÕES FINAIS}

Objetivou-se com este estudo demonstrar como ocorre a evidenciação do Patrimônio Líquido em uma organização sem fins lucrativos de acordo com a Teoria dos Fundos. Para tanto, adaptou-se as demonstrações financeiras de uma organização sem fins lucrativos elaboradas em conformidade com a Lei 6.404/76 à proposta da contabilidade por fundos, evidenciadas no pronunciamento do SFAS 117.

Os dados revelaram que a segregação por fundos apresenta um maior valor informacional, ao destacar a característica de cada recurso e de delimitar seu uso (restrito ou irrestrito) e possibilitar a identificação de sua variação por tipo de fundo. Esse aspecto demonstra maior transparência nas informações e reflete maior austeridade com a aplicação dos recursos gerados ou disponibilizados para a consecução de seu objetivo social. 
Conclui-se que a Contabilidade por Fundos seria a mais adequada para a evidenciação das informações contábeis das entidades sem fins lucrativos, ao demonstrar mais claramente a origem e aplicação dos recursos. Desse modo, pode ser considerado um importante instrumento de controle e de accountability das ações tanto dos gestores quanto da organização como um todo, devido ao grau de detalhamento e sua utilidade informacional.

Sob a ótica do usuário interno, pode-se dizer que a contabilidade por fundos pode funcionar como eficaz instrumento de controle e acompanhamento das diretrizes orçamentárias, ao possibilitar a mensuração dos recursos, custos, despesas, resultados e patrimônio de cada fundo, bem como a contribuição de cada um deles no efetivo cumprimento da missão da instituição.

\section{REFERÊNCIAS}

ABE, C. H. S. Teorias Contábeis sobre o Patrimônio Líquido e Teoria da Renda Acréscimo Patrimonial: Um Estudo Interdisciplinar. 2007. Dissertação (Mestrado em Ciências Contábeis). Faculdade de Economia, Administração e Contabilidade, Universidade de São Paulo, São Paulo, 2007.

AMERICAN INSTITUTE OF CERTIFIED PUBLIC ACCOUNTANTS (AICPA). Government Accounting Standards Board (GASB) Statement No. 54. Fund Balance Reporting and Governmental Fund Type Definitions. Disponível em: http://www.aicpa.org/interestareas/businessindustryandgovernment/resources/governmentreso urcecenter/guidance/downloadabledocuments/gov't\%20brief_jun'10.pdf

ANDRADE, G. A. Contabilidade de entidades sem fins lucrativos. In: Curso sobre Temas Contábeis. Conselho Regional de Contabilidade do Estado de São Paulo. São Paulo: Atlas, 1991.

BATISTA, A. A. R. Como Mensurar o Patrimônio Líquido de uma Empresa? Estudo das metodologias alternativas segundo a concepção da Teoria da Contabilidade. In:

CONVENÇÃO DE CONTABILIDADE DE MINAS GERAIS, 4, 2003, Belo Horizonte.

Disponível em

<http://www.sinescontabil.com.br/monografias/trab_profissionais/ivconvencao/ana_angelica_ teoria_da_contabilidade.htm> Acesso: 02 de Junho de 2008.

D`AURIA, F. Contabilidade Geral (Teoria da Contabilidade Patrimonial). São Paulo: Companhia Editora nacional, 1956.

FINANCIAL ACCOUNTING STANDARD BOARDS (FASB). Statement Financial

Accounting Standards $\mathbf{n}^{\mathbf{0}}$ 117. Financial Statement of Nor-for-profit organizations. Financial Accounting Standards Board. June, 1993. Disponível em:

http://www.fasb.org/cs/BlobServer?blobcol=urldata\&blobtable=MungoBlobs\&blobkey=id\&b lobwhere $=1175820923228 \&$ blobheader $=$ application $\% 2 \mathrm{Fpdf}$ 
FREEMAN, R. J.; SHOULDERS, C. D. Governmental and nonprofit accounting: theory and practice. 4. ed. New Jersey: Prentice Hall, 1993.

GIL, A. C. Métodos e técnicas de pesquisa social. 6. ed. São Paulo:Atlas, 2010.

HENDRIKSEN, E. S.; VAN BREDA, M. F. Teoria da contabilidade. 1. ed. São Paulo: Atlas, 2007.

HUSBAND, G. R. The corporate-entity fiction and accounting theory. The Accounting Review, v. 8, p. 241-253, 1938.

INTERNATIONAL FINANCIAL REPORTING STANDARDS (IFRS). Conceptual Framework, 2012. Disponível em:

http://eifrs.ifrs.org/eifrs/bnstandards/en/2013/conceptualframework.pdf

IUDÍCIBUS, S. Teoria da contabilidade. 10 ed. São Paulo: Atlas, 2010.

KAM, V. Accounting theory. New York: John Wiley e Sons, 1986.

LI, D. H. The nature of corporate residual equity under the entity concept. In: The Accounting Review, v. 35, p. 258-263, April, 1960.

LITTLETON, A. C. Essays on Accountancy. Urbana: University of Illinois Press, 1961.

MARCOVITCH, Jacques. Da exclusão à coesão social: profissionalização do terceiro setor. In: $3^{\circ}$ Setor: Desenvolvimento Social Sustentado. Rio de Janeiro: Paz e Terra, 1997.

MELO, V.P.; FISCHER, T.; SOARES Jr, J. S. Diversidades e confluências no campo do terceiro setor: um estudo de organizações baianas. Anais... ENAPAD, XXVII, Atibaia, 2003.

NIYAMA, J. K.; SILVA, C. A. T. Teoria da contabilidade. São Paulo: Atlas, 2010.

OLAK, P. A.; NASCIMENTO, D. T.: Contabilidade para entidades sem fins lucrativos (Terceiro Setor). São Paulo: Atlas, 2010.

OLAK, P. A. Contabilidade de entidades sem fins lucrativos não governamentais. 1996. Dissertação (Mestrado em Ciências Contábeis). Faculdade de Economia, Administração e Contabilidade, Universidade de São Paulo, São Paulo, 1996.

SUMMERS, Edward Lee. Accounting information systems. 2. ed. New Jersey, 1991. 
VATTER, W. J. Corporate Stock Equities: Part I. In: BACKER, M. Handbook of modern accounting theory. Englewood Cliffs, NJ: Prentice-Hall, p. 361-383, 1963.

R. Cont. Ufba, Salvador-Ba, v. 7, n. 2, p. 04-21, maio-agosto 2013 